\title{
Bio Core
}

Exploring Scientific Community

\section{International Journal of Nutritional Science and} Food Technology

Review Article

\section{How to Preserve our Health with a Healthy Diet and Herbs}

Dragan Jovanov*

Environmental Resources and Food Security Management, MIT University, Skopje, Macedonia, USA.

Corresponding author: Dragan Jovanov, Environmental Resources and Food Security Management, MIT University, Skopje, Macedonia, USA. Tel: +38970867356, E-mail: daci.j@hotmail.com

Citation: Dragan Jovanov (2016), How to Preserve our Health with a Healthy Diet and Herbs. Int J Nutr Sci \& Food Tech. 1:1, 03-07. DOI: 10.25141/2471-7371-2016-1.0033

Copyright: (C2016 Dragan Jovanov. This is an open-access article distributed under the terms of the Creative Commons Attribution License, which permits unrestricted use, distribution, and reproduction in any medium, provided the original author and source are credited

Received December 8, 2015; Accepted December 16, 2015 Published February 20, 2016

\section{Introduction}

What is healthy food? Healthy food means an input, balanced amount of protein, carbohydrates, fats, vitamins, minerals etc. That means entering larger amounts of protein and carbohydrates and less fat. In the diet is especially important to consume vitamins and minerals, mostly found in fresh fruits and vegetables. Healthy eating helps in enhancing the natural immunity of the body and allows easier defend against the damaging effects of many diseases. With a healthy diet, as well as regular physical activity, gradually will reduce the excess body weight, which is a common risk factor for many diseases.

Top 10 Healthiest Foods on the Planet, according to Dragan Jovanov

1. Lemons

Why They're Healthy: Just one lemon has more than 100 percent of your daily intake of vitamin C, which may help increase "good" HDL cholesterol levels and strengthen bones. Citrus flavonoids found in lemons may help inhibit the growth of cancer cells and act as an anti-inflammatory.

Quick Tip: Add a slice of lemon to your green tea. One study found that citrus increases your body's ability to absorb the antioxidants in the tea by about 80 percent.

\section{Broccoli}

Why It's Healthy: One medium stalk of broccoli contains more than 100 percent of your daily vitamin $\mathrm{K}$ requirement and almost 200 percent of your recommended daily dose of vitamin C, two essential bone-building nutrients. The same serving also helps stave off numerous cancers.

Quick Tip: Zap it! Preserve up to 90 percent of broccoli's vitamin $\mathrm{C}$ by microwaving. (Steaming or boiling holds on to just 66 percent of the nutrient.)

\section{Dark Chocolate}

Why It's Healthy: Just one-fourth of an ounce daily can reduce blood pressure in otherwise healthy individuals. Cocoa powder is rich in flavonoids, antioxidants shown to reduce "bad" LDL cholesterol and increase "good" HDL levels.

Quick Tip: A dark chocolate bar contains about 53.5 milligrams of flavonoids; a milk chocolate bar has fewer than 14 .

\section{Potatoes}

Why They're Healthy: One red potato contains 66 micrograms of cell-building folate - about the same amount found in one cup of spinach or broccoli. One sweet potato has almost eight times the amount of cancer-fighting and immune-boosting vitamin $\mathrm{A}$ you need daily.

Quick Tip: Let your potato cool before eating. Research shows that doing so can help you burn close to 25 percent more fat after a meal, thanks to a fat-resistant starch.

\section{Salmon}

Why It's Healthy: A great source of omega-3 fatty acids, which have been linked to a reduced risk of depression, heart disease, and cancer. A 3-ounce serving contains almost 50 percent of your daily dose of niacin, which may protect against Alzheimer's disease and memory loss.

Quick Tip: Opt for the wild over farm-raised, which contains 16 times as much toxic polychlorinated biphenyl (PCB) as wild salmon.

\section{Walnuts}

Why They're Healthy: Contain the most omega-3 fatty acids, which may help reduce cholesterol, of all nuts. Omega-3s have been shown to improve mood and fight cancer; they may protect against sun damage, too (but don't skip the SPF!).

Quick Tip: Eat a few for dessert: The antioxidant melatonin, found in walnuts, helps to regulate sleep.

\section{Avocados}

Why They're Healthy: Rich in health, satisfying fats proven in one study to lower cholesterol by about 22 percent. One has more than half the fiber and 40 percent of the folate you need daily, 
which may reduce your risk of heart disease.

Quick Tip: Adding it to your salad can increase the absorption of key nutrients like beta-carotene by three to five times compared with salads without this superfood.

\section{Garlic}

Why It's Healthy: Garlic is a powerful disease fighter that can inhibit the growth of bacteria, including E. coli. Allicin, a compound found in garlic, works as a potent anti-inflammatory and has been shown to help lower cholesterol and blood-pressure levels.

Quick Tip: Crushed fresh garlic releases the most allicin. Just don't overcook; garlic exposed to high heat for more than 10 minutes loses important nutrients.

\section{Spinach}

Why It's Healthy: Spinach contains lutein and zeaxanthin, two immune-boosting antioxidants important for eye health. Recent research found that among cancer-fighting fruits and veggies, spinach is one of the most effective.

Quick Tip: Spinach is a healthy and flavorless, addition to any smoothie. You won't taste it, we promise! Try blending 1 cup spinach, 1 cup grated carrots, 1 banana, 1 cup apple juice, and ice.

\section{Beans}

Why They're Healthy: Eating a serving of legumes (beans, peas, and lentils) four times a week can lower your risk of heart disease by 22 percent. That same habit may also reduce your risk of breast cancer.

Quick Tip: The darker the bean, the more antioxidants it contains. One study found that black bean hulls contain 40 times the amount of antioxidants found in white bean hulls.

\section{Ten advices for our health according to Dragan Jovanov}

1. It is wrong to think that if you drink water in big quantity, you will become fat. Water should be consumed during meals, in the morning through the lunch and at night before bedtime.

2. It is not true that grapefruit and pineapple help for disintegration on the fats. Grapefruit and pineapple are useful to remove toxic substances from the body.

3. Black bread is better than white bread. In fact, black bread contains vitamin B group, iron and cellulosic fibers, rather than baked goods.

4. The meals should be divided into several small meals because this way the chances to get fat are small. The stomach consumes energy for every food that you eat, during the each digestion process the stomach spends energy.

5. It is wrong opinion that is compulsory to eat a warm meal at least once a day.

6. It is true that too much salty food can damage your organism. It's better to use sea salt.

7. At the beginning of a meal you should eat fruit, it arrives directly in the intestines, not holding long in the stomach. So the fruit is digested fast and you don't feel hunger.

8. It is not true that the stomach will be reduced if you eat less. Stomach anatomical doesn't change. Simple, it just gets used to smaller quantities of food and after some time the feel of hunger is smaller.

9. If we eat slowly the feeling of fullness comes quickly. It is why it is better to taste the food slowly, to smell the food longer. In this way you will fill surfeit and you won't need more food.

10. The most dangerous fats in the food are those that are less noticeable.

Fruits and vegetables: The richest natural sources of vitamins and minerals

Fruits and vegetables are rich with vitamins and minerals, which are natural defensive ingredients against many diseases in the human body. Scientists have not yet discovered all the nutrients that act to protect the body from many diseases. Therefore, it is recommended vitamins and minerals to be entered through vegetables and fruit, not by synthetic products, various accessories or food extracts, which can be purchased at pharmacies. These synthetic manufactured sources of vitamins and minerals are not effective, because they don't contain all the useful nutrients. Theoretically, the fruit and the vegetables are divided into seven colors and it is recommended the principle of "seven colors of health". This is important because in the daily diet we will bring food with a variety of colors, including the following groups:

Red - tomato and tomato products.

These foods contain substances for which it is proved that they lower the risk of several types of cancer, including prostate cancer.

Red and pink - grapes, grape juice, red wine, dried plums, strawberries and blackberries.

These foods contain powerful antioxidants that have an effective impact on heart health, because they prevent the occurrence of clots in blood vessels. Also, as strong antioxidants in this fruit protects the body from some carcinogens disease.

Orange - carrot and apricot.

Carrot and apricot contain beta-carotene, which improves communication between cells, this is helping them to be stronger in the combat the spread of cancer.

Orange-yellow - orange, orange juice, mandarin, grapefruit, lemon, papaya, pineapple and peach.

This fruit is rich in vitamin $\mathrm{C}$, a strong antioxidant, which increases the body's resistance to infection. Also, this fruit serves as a protection against many diseases, including malignant diseases.

Yellow, green - yellow corn, peas and avocado.

These foods contain lutein, which is a strong antioxidant and protects the retina (retina) of the eye from radiation and reduces the risk of visual impairment. A growing number of studies show that lutein, thanks to its antioxidant properties has great importance to the preservation of vision, healthy skin, for protection of the heart, protection of the cervix, as well for strengthening the immune system. The boiled vegetables are the best sources of lutein. In the fresh vegetables, lutein is captured in cellular structures, while with digestion enables absorption and increased bioavailability.

Green - cabbage, kale and cauliflower.

This vegetable contains substances that reduce the formation of 
harmful substances in the liver. They help in maintaining the health of the liver, which is the main laboratory of the body, an organ that destroys all the toxins from the body.

White-Green - garlic and onions.

Garlic and onions have numerous medicinal ingredients that increase the natural immunity of the organism. They protect against many infections, for example they are useful in improving the heart and blood vessels, liver, lung. Also, they are useful in case of cancer of the prostate. Amino acids from the garlic are effective to reduce the bad cholesterol in the plasma and to increase the concentration of good cholesterol and triglycerides. This vegetable protects the DNA.

Another white-green fruits and vegetables, such as artichoke, pears, asparagus, celery and mushrooms are rich in flavonoids, antioxidants that protect the cell membranes.

\section{How to preserve our health with a healthy breakfast}

\section{Reasons you should not skip breakfast.}

When you were little, probably your mother told you that breakfast is the most important meal of the day. Although this sentence is inserted in your head, you often in the morning hurry to get out the door without having a breakfast or maybe because you think that if you skip the breakfast you will be slim. Every time when you skip your breakfast it is a big mistake that affects your health and your appearance. Some people skip breakfast in an effort to lose weight, but that's not a good idea. It can backfire.

Skipping meals, especially breakfast, can actually make weight control more difficult. Breakfast skippers tend to eat more food than usual at the next meal, or nibble on high-calorie snacks to stave off hunger.

Some studies suggest that people tend to add more body fat when they eat fewer, larger meals than when they eat the same number of calories in smaller, more frequent meals. Other studies show that weight management can be equally effective without breakfast.

\section{Why You Should Eat a Healthy Breakfast}

1. The breakfast improves concentration, vitality and energy through the day. Breakfast not only supplies your body with energy, but also nourishes your brain. Children who regularly eat breakfast have better results in school and adults are more productive and responsible on the job. Eating breakfast in the morning improves concentration and helps you to stay focused.

2. Eating breakfast will make you feel surfeit, not to feel hungry. Probably you have felt that it is difficult to concentrate while your stomach is empty, when you feel hunger.

3. The breakfast increases energy. People who start their day with breakfast have more energy during the day and are more physically resistant. This means that if you eat breakfast, it is more probability to keep a hard fitness hour and to shape up your body. Before and after exercise there should be space of one hour for eating a food, because with a full stomach is not advisable and it is hard to exercise.

4. The breakfast improves mood. When people eat breakfast, they are increasing the level of serotonin in the brain, which results in a feeling of well-being. If you don't eat breakfast, it is more likely to be irritable and anxious. Studies have shown that those who eat breakfast regularly suffer less from anxiety, depression and hyperactivity.

5. The breakfast accelerates the metabolism. When you don't eat breakfast for a long period, at night the body begins to think that you are starving and the body store more fat. Breakfast stimulates metabolism and encourages the body to burn calories.

6. The breakfast controls the appetite. Although you may think that your morning starvation will reduce calorie intake and accelerate weight loss, the reality is that that is wrong. If hungry early in the day, later you will be more inclined to overeat. People who don't eat breakfast, instead, good they do worse and no healthy food choices on the rest of the day.

7. Breakfast reduces the risk of diabetes. If you eat breakfast in the morning, then the possibility to be diseased of diabetes, obesity and cardiovascular disease are small.

\section{Why Kids Need Breakfast?}

While adults need to eat breakfast each day to perform their best, kids need it even more. Their growing bodies and developing brains need regular refueling often, from food. When kids skip breakfast, they don't get what they need to be at their best. Short on time? Eating a wholesome, nutritious morning meal will probably save you time in the long run. By recharging the brain and body, you'll be more efficient in just about everything you do.

Interestingly, studies show that kids who skip breakfast are tardy and absent from school more often than children who eat breakfast on a regular basis. Preparing a good breakfast can be as quick and easy as splashing some milk over cereal, or making oatmeal or a healthy smoothie.

You could also consider enrolling your children in a school breakfast program, if possible, or pack a breakfast brown bag or smoothie the night before that they can eat on their way to school.

Skipping breakfast has pretty consistently been linked to health risks - high blood pressure, overweight, and an unhealthy assortment of blood-fats, among them. But what's interesting is that the health effects of skipping breakfast - even being overweight - don't seem to be the result of indulging in extra "make-up" meals throughout the day. So it's not about just the calories: There seems to be something else at play. The short answer may be that skipping the early meal keeps your body in the stressful state of fasting for longer, which can disrupt your metabolism in considerable and, apparently, life-threatening, ways.

The new study out of Harvard looked at the health records of nearly 27,000 men, all health care professionals $45-82$ years old when the study began. The team looked for correlations in lifestyle choices - e.g., Skipping breakfast - and health outcomes over a period of about 16 years.

Men who skipped breakfast were $27 \%$ more likely to experience a heart attack or to die as the result of coronary heart disease. The men who skipped breakfast were more likely to be single, smokers, employed full-time, to drink more alcohol, were younger, and were less likely to be physically active than people who ate breakfast. Controlling for a slew of these and other risk factors for heart disease - like alcohol consumption, smoking history, body mass index, regular doctor visits, quality of diet, TV watching, activity level, and sleep habits - did reduce the link between skipping breakfast and heart disease, but didn't obliterate it. The number of times per day the men ate wasn't linked to heart risk. 
The reason that skipping breakfast is linked to coronary heart disease is because it seems to give rise to a group of risk factors that collectively raise heart risk. Prolonged fasting, leads to increases in diastolic and systolic blood pressure, blood concentrations of insulin, triglycerides, free fatty acids and LDL-cholesterol, and to decreases in blood concentrations of HDL-cholesterol.

\section{You don't have time for rich breakfast? Here are three healthy and quick breakfast ideas.}

- Oatmeal with milk. Mix oat flakes with milk, add a few thin slices apples and raisins or dried cranberries.

- Integral bread covered with peanut butter and apple.

- Hard-boiled eggs, integral bread and banana.

\section{Seven of the healthiest herbs and spices that will improve your health}

Spices and herbs are not only enriching the taste of the food, but also gives us the positive health benefits. The healing power of some of them has been used thousands of years ago, it has been proven. Herbs help in the prevention and treatment of many diseases.

\section{Cinnamon}

To regulate the blood sugar levels in diabetics, Put half teaspoon cinnamon in oatmeal or spice the milk with a little cinnamon. Cinnamon is so tasty that you would never think that possesses great healing power. Besides regulating blood sugar levels in diabetics, if you consume half or a quarter teaspoon of cinnamon twice a day it will reduce the triglycerides and cholesterol levels by about $30 \%$. Cinnamon has anti-inflammatory and antibacterial properties. The cinnamon is really effective in fight against escherichia coli and other bacteria. In some people the cinnamon reduces the unpleasant symptoms of heartburn.

\section{Ginger}

Ginger is used to treat nausea and abdominal pain, to relieve the pain of arthritis and many others. The ginger is especially useful in case of nausea and vomiting. He can eliminate the stomach problems and the ginger reduces the headache caused by migraine.

\section{Sage}

Sage is used in the treatment of sore throat, to protect the memory etc. If you have a problem with the stomach or if you have a dry and sore throat, you should drink a tea of sage. The sage tea reduces the throat pain, can facilitate the symptoms of Alzheimer's disease. The sage tea is useful for better memory, good mood etc.

\section{Rosemary}

Rosemary improves concentration and brain function. The rosemary is a powerful antioxidant, it increases blood flow to the brain and protects the brain from the free radicals, thereby is reducing the risk of stroke and diseases such as Alzheimer's disease. This herb increases alertness and concentration and that results with the effective execution of the tasks associated with the memory. The rosemary is often used for marinating of the meat. It contains acids, and substances that prevent spoilage of the meat. The rosemary also stimulates the immune system, improves circulation and improves digestion of food.

\section{Mint}

Mint use for improving the digestion in the organism, for abdominal pain and many other uses. Traditionally, the mint tea is used to relieve pain in the stomach, but also the mint tea improves the digestion of the food. The mint tea helps in case of diarrhea, stomach gas (flatulence) and the stomach irritable bowel syndrome. Efficient, effective of the mint tea can come to the fore in the case of reduction of the vomiting urge. This tea is often used to treat the common cold, sore throat, sinus problems and respiratory infections. The oil of peppermint can help to reduce headache, muscle pain and toothache.

\section{Parsley}

Parsley helps for strong immunity, prevention of heart attack and other. The parsley is a rich source of vitamins A and C, helps to strengthen the immune system and is very easy to protect the cardiovascular system. The tea from parsley is used to relieve the symptoms of urinary tract infection. Chewing the parsley will help you to remove the bad breath.

\section{Turmeric}

Turmeric has anticancer properties. The turmeric is a spice that gives the curry yellow color, and it is mostly used in Indian medicine. In recent years, studies show that his power is great to fight against the worst and the most common disease in this century is cancer. The turmeric consists of substances which reduce the growth of tumors. This substance protects against colon cancer, melanoma, and the most lethal form of skin cancer.

\section{Herbs for protection of the respiratory system}

Sambucus nigra, Thymus serpyllum, Salvia officinalis, Plantago major, Sideritis Scardica, Origanum vulgare, Ocimum basilicum.

\section{Medicinal plants for protection of the stomach}

Centaurium erythraea, Hypericum perforatum, Mentha piperita, Gentiana lutea, Artemisia absinthium, Matricaria chamomilla, Urtica dioica, Rúbus idáeus, Rubus fruticosus.

\section{Medicinal plants for protection of the heart}

Crataegus oxyacantha, Matricaria chamomilla, Hypericum perforatum, Humulus lupulus, Lavandula officinalis, Valeriana officinalis, Mellisa officinalis.

\section{Medicinal plants for protection of the liver}

Arctium lappa, Helichrysum arenarium, Centaurium erythraea, Onopordum acanthium, Taraxacum officinale.

\section{Medicinal plants for protection of the cancer}

Geranium robertanium, Artemisia Annua, Aloe Vera, Chelidonium majus, Urtica dioica, Seeds from bitter apricot, Oil from bitter melon or bitter apricot, Aronia arbutifolia.

\section{Solidarity with hungry people in the world}

I Dr. Dragan Jovanov am solidarity with the people from over the world who suffer from hunger. This global problem, recent years, is attacking the world. My advice for the countries with poor economic development is to make projects from all parts of the world where there is a problem such as this. To open soup kitchens where the people can feed, to give one-time assistance to socially vulnerable people. I am ready at any moment to help all people in the world, through Phyto-medicine, to maintain their health vital, and to have a healthy food. Because we are all human and we 
are all visitors here on this planet. You, me and everybody should help everyone, and certainly the humanity knows no borders, the more we help the people, the more we are mentally and socially stronger as people.

They're oversized, huge, enormous companies in the world which should come on the world stage and to donate or to invest in countries with weak economic growth and in the countries where the hunger is increasingly gaining momentum. It is sad that in this century, where there are so much innovation, huge development of the whole society and in the same time we are still faced with this problem of hungry people. The world organization should put an effort in order to really solve this important problem, to decrease this huge number of hungry people. I helped to more than 20 thousand people and all this alone, me as a product of myself, of my own will. Just think, take my example, you can do too!! By changing yourself you are changing the world!! 